\title{
ONLINE MEASUREMENT METHOD OF WATER QUALITY IN THE SULEJOW RESERVOIR
}

\author{
METODA POMIARU “ON-LINE” PARAMETRÓW JAKOŚCIOWYCH WODY \\ W ZBIORNIKU SULEJOWSKIM
}

\begin{abstract}
The paper presents methodology of accurate mobile measurements of water quality parameters such as temperature, dissolved oxygen, chlorophyll "a" concentration, ammonium ion concentration, conductivity, $\mathrm{pH}$ and blue-green algae content in water. The measurements (probe EXO 2, YSI, USA) were made on various depths of probe immersion (1.5, 2.5 and $3.5 \mathrm{~m}$ ) and at different towing speeds of the probe (approx. 5.4 and $9.0 \mathrm{~km} / \mathrm{h}$ ). Static measurements carried out on the same route provided reference values for the measurements in motion to compare the repeatability of static and mobile methods. The tests were also evaluated by observation of probe behavior in motion, e.g. water disturbance intensity, access of light (sun rays) to the sensors. Statistical tests confirmed that the mean values of water quality parameters from mobile measurements with the speed of $5.4 \mathrm{~km} / \mathrm{h}$ at the depth $1.5 \mathrm{~m}$ does not differ from the stationary measurements. Results of statistical analysis prove that water quality parameters can be measured accurately keeping established speed of towing the probe at the fixed depth. Methodology of mobile measurements elaborated in the frame of this work allows to collect vast number of data which can be used to obtain GIS point maps of water quality parameters in large water bodies.
\end{abstract}

Keywords: surface water monitoring, mobile measurements, statistical analysis, GIS, MONSUL project

\section{Introduction}

Surface waters of rivers, lakes and artificial reservoirs are subject to anthropogenic impact [1]. For this reason, they should be placed under particular protection and all activities in their vicinity should be well considered, assessed and periodically controlled $[2,3]$. Water in artificial reservoirs created by planned actions for various purposes, e.g. as drinking water storage or for tourism, recreation and sports should be of high quality.

The Sulejow Reservoir was built in the early 1970s. The Reservoir functions are evolving; starting out as a place to store water to what is now an important place for recreation, water sports and a unique and very complex ecosystem with variety of plant and animal species. The Reservoir evolution strongly impacted the local economy, farming,

\footnotetext{
${ }^{1}$ Faculty of Process and Environmental Engineering, Lodz University of Technology, ul. Wólczańska 213, 90-924 Łódź, Poland

${ }^{2}$ Faculty of Geographical Sciences, University of Lodz, ul. G. Narutowicza 88, 90-139 Łódź, Poland

*Corresponding author: aleksandra.zieminska-stolarska@p.lodz.pl
} 
water retention and microclimatic conditions. The water condition is degrading due to unconstrained volumes of pollutants that are draining into the Reservoir, resulting in the excessive growth of blue-green algae [4-8]. This process as harmful and dangerous for every way of using the natural qualities of the reservoir must be assessed, predicted and minimized [9].

In the beginning of 2015, the MONSUL research project was started on the Faculty of Process and Environmental Engineering of the Lodz University of Technology (http://www.monsul.wipos.p.lodz.pl), implemented in collaboration with the Faculty of Geographical Sciences of the University of Lodz and the Norwegian Institute for Water Research (NIVA) of Oslo.

A system of direct and continuous monitoring measurements covering virtually the entire surface area of the Sulejow Reservoir was developed. The monitoring programme launched within the framework of the MONSUL project based on a mobile, floating measuring system equipped with an EXO2 probe and GPS was carried out in following stages: measurements, modelling of water quality in the reservoir, sharing the results with regional and national institutions, controlling the water quality in the ecosystem of the Sulejow Reservoir.

The main purpose of this paper is to present the results of mobile monitoring of selected water quality parameters using a multi-parameter probe which for such a big water body was performed for the first time in the literature.

Test drives and measurements were performed to determine optimal conditions (depth of immersion of the probe and the speed of the motorboat) for the correct measurements of water quality parameters. Data collected during mobile measurements, after GIS processing, enabled to display map of water quality parameters in the Reservoir.

\section{Research method}

The measurements of water quality parameters were performed in two variants: 1 - with stationary measurement in one, constant location point for the measurement probe (buoy anchored near the Reservoir's dam); 2 - with a mobile instrument, during the flow of the probe attached to a boat driven along a planned route, over as large surface of the Reservoir as possible.

The measurement set used for testing consisted of EXO 2 probe (YSI, USA) with the DT80 (TECHNIKA IT SA, Gliwice, Poland) - measurement data collection and transmission system $[10,11]$.

The sensors of the probe provide continuous, automatic measurements of the following parameters of water: temperature, $\mathrm{pH}$, dissolved oxygen concentration, conductivity, chlorophyll and blue green algae (BGA) concentration, ammonium ion concentration. The frequency of probe measurements and periods of data transmission to the operator's server were adjustable - measurements were set to be taken every two minutes, data transmission every two hours.

Furthermore, the buoy was additionally equipped with a meteorological sensor measuring air temperature and humidity (relative and absolute), wind speed and direction, atmospheric pressure and insolation.

The ultimate assumption of the programme of mobile measurements with a multi-parameter probe was to drive the motorboat along the entire length of the Sulejow Reservoir - from the dam to the town of Barkowice - along the set route ("zig-zag") in order 
to obtain data from the main water flow course as well as form bays, marinas and river mouths.

The measurement data of water parameters, together with the exact time and location (GPS system data), were collected in the memory cache of a mobile datalogger and transmitted to a PC computer. For the purpose of measurements in motion, a special extension boom was constructed and installed on the motorboat. The extension boom enabled the installation of the measurement probe with controlled immersion depth adjusted for measurement requirements and access to the probe for observation and periodic cleaning purposes. The length of the extension boom amounted to approx. $0.8 \mathrm{~m}$, which ensured the elimination of the impact of water waving and whirling created by the motorboat movement and drive on measurement sensors. Mobile measurements were taken with the system schematically presented in Figure $1 \mathrm{a} 12 \mathrm{~kg}$ metal weight was attached to the towing line, to which the $3.6 \mathrm{~kg}$ probe was fixed. During the drive, the hydrodynamic resistance of water resulted in lifting the probe; the weight compensated this effect and stabilized the position of the probe in water (eliminated whirling and waving). During the travel with the speed of approx. $5.4 \mathrm{~km} / \mathrm{h}$, this set provided a stable probe position with the measurement sensors at the depth of approx. 1.3 m under the water surface (Fig. 1b).

a)

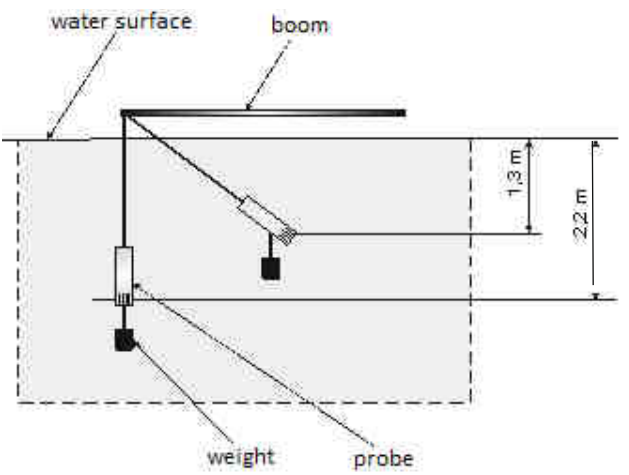

b)

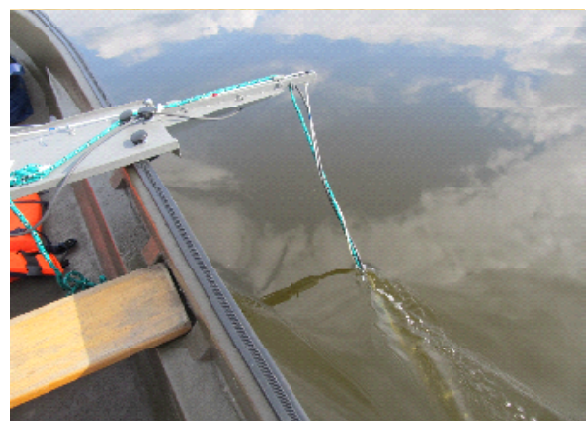

Fig. 1. a) Diagram of the measurement probe with weight in stationary conditions (probe sensors immersion depth approx. $2.2 \mathrm{~m}$ ) and in approx. $5.4 \mathrm{~km} / \mathrm{h}$ travel (probe sensors immersion depth approx. $1.3 \mathrm{~m}$ ); b) Photograph shows the mounting of the probe on the motorboat moving at speed of approx. $5.4 \mathrm{~km} / \mathrm{h}$

The testing involved driving the motorboat at a constant speed along the same route (of approx. $2 \mathrm{~km}$ ) several times. Two speeds were taken into consideration: approx. $5.4 \mathrm{~km} / \mathrm{h}$ and approx. $9 \mathrm{~km} / \mathrm{h}$. The probe, towed at a specific immersion depth made "on-line" measurements of seven water parameters: temperature, $\mathrm{pH}$, dissolved oxygen concentration, conductivity, chlorophyll concentration, blue green algae (BGA) concentration, ammonium ion concentration and collected data regarding the time and location of the probe at the moment of measurement. During the flow the boat was stopped 4-5 times for stationary measurements which provided reference values for the results of measurements in motion and stationary. The objective was to confirm the repeatability of results obtained with these two methods. The second variable parameter during the testing 
drives was the immersion depth of the probe - 1.5 and $2.5 \mathrm{~m}$ depths were tested. The tests were also evaluated by observation of probe behavior in motion, e.g. water disturbance intensity, access of light to the sensors. A series of measurements of the water quality in the Sulejow Reservoir to assess accuracy the mobile methodology [12] were carried out in May 2015 and September 2016. An example of a route for the motorboat measurements in one day tracked with a GPS system is presented in Figure 2.

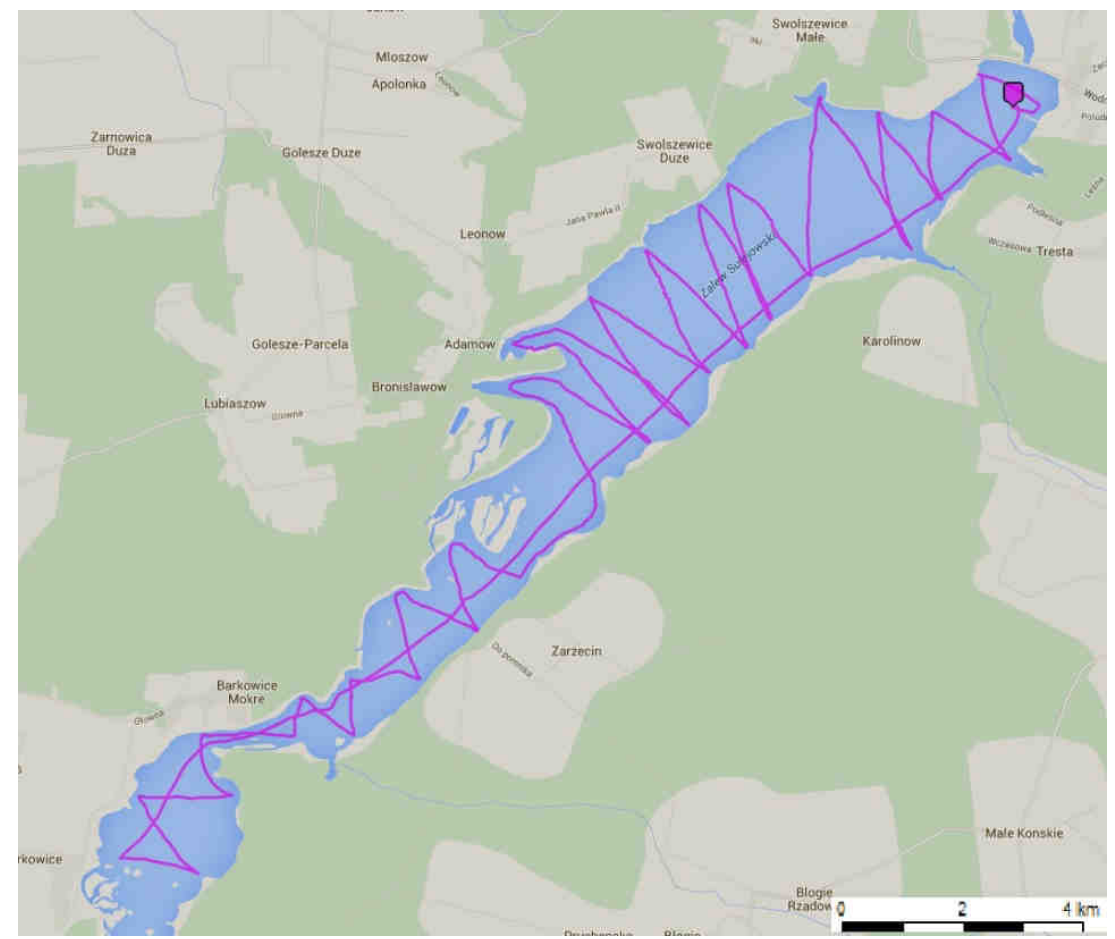

Fig. 2. An example of a route for the motorboat for mobile measurements in one day tracked with a GPS system

\section{Objective and scope of the analysis}

The objective of the analysis of data obtained during the preliminary testing was the evaluation of the effect of motorboat speed on the results of measurements of water quality parameters. The purpose was to determine whether the results of measurements in motion are significantly different from the measurements of the same parameters in stationary conditions, i.e. when the probe is immersed at the chosen depth and remains motionless.

The evaluation of the effect of boat speed on the results of measurements requires the acceptance or rejection of the hypothesis that the results of stationary and mobile measurements belong to the same population, i.e. that the calculated mean values of selected parameters measured with the probe that was stationary or towed behind the boat are the same and do not differ in any significant manner. 
Formally, the task involves the verification of the statistical hypothesis claiming that the results of measurements obtained during the motion and the results of stationary measurements results belong to the same population and the expected values of these populations are equal. The hypothesis can be written down as (1):

$$
H_{0}: \mu_{1}=\mu_{2}
$$

where $\mu_{1}, \mu_{2}$ are mean values from stationary and mobile measurements of each, measured parameter.

The $H_{0}$ hypothesis was formulated as follows: "The expected (mean) value calculated from the results of stationary measurements at the depth $h=1.5 \mathrm{~m}$ is not significantly different from the mean value calculated from measurements in motion with the speed of $v=5.4 \mathrm{~km} / \mathrm{h}$ ". Indicated depth was selected due to the fact that the probe when towed by boat at the speed of $v=5.4 \mathrm{~km} / \mathrm{h}$ is also immersed at the depth of approx. $1.5 \mathrm{~m}$.

The following test function (2) was used to verify the hypothesis $H_{0}$ :

$$
u=\frac{\overline{x_{1}}-\overline{x_{2}}}{\sqrt{\frac{\sigma_{1}^{2}}{n_{1}}+\frac{\sigma_{2}^{2}}{n_{2}}}}
$$

where: $\overline{x_{1}}, \overline{x_{2}}$ - average values of measured parameters, $\sigma_{1}^{2}, \sigma_{2}^{2}$ - variances of measured parameters, $n_{1}, n_{2}$ - number of observations.

After the calculation of the value of the test function $u$, the $H_{0}$ hypothesis was tested and compared to the alternative hypothesis $\mathrm{H}_{1}: \overline{x_{1}} \neq \overline{x_{2}}$. In this case, we need to take into account the bilateral critical area, i.e. we discard $H_{0}$ if the calculated value of $u$ is higher than $u_{k}=2.04$ (with the assumed confidence level $\alpha=0.05$ ).

\section{Results and discussion}

First, the verification was made whether the towing of the probe with the speed of boat approx. $5.4 \mathrm{~km} / \mathrm{h}$ can significantly impact on the measurements parameters. For this purpose, the authors tested the statistical hypothesis on the level of significance of $\alpha=0.05$ stating that the results of measurement obtained during motorboat drive with the speed of $5.4 \mathrm{~km} / \mathrm{h}$ are not significantly different from the results of stationary measurements with a motionless probe immersed to the depth of $h=1.5 \mathrm{~m}$.

Data from Tables 1-3 were used to verify the $H_{0}$ and $H_{1}$ hypothesis. For each of the measured water quality parameters, the value of test function $u$ described with the equation (2) was calculated and compared with the critical value of $u_{k r}$ read from t-Student tables. For the assumed level of confidence $\alpha=0.05$ and $n_{1}+n_{2}-2$ degrees of freedom, the critical value of test (2) is $u_{k r}=2.04$. The variances of measured parameters presented in Table 1 were determined by the independent measurements that were performed on the studied area.

Table 4 presents the results of calculations and values of the test function $u$ determined for each of the measured water quality parameters.

The data presented in Table 4 show that for all measured water quality parameters, the calculated value of the test function $u$ is lower than the critical value $u_{k r}=2.04$. This means that there are no reasons to reject the hypothesis that the mean values calculated from the results of stationary measurements at the depth $h=1.5 \mathrm{~m}$ are not significantly different from the mean values calculated from the measurements in motion with the speed of $v=5.4 \mathrm{~km} / \mathrm{h}$. 
Based on this result, a conclusion can be drawn that towing the probe with the established speed of $v=5.4 \mathrm{~km} / \mathrm{h}$ does not distort the results of measurements.

Table 1

Results of the measurements of water quality parameters with a motionless probe immersed at the depth $h=1.5 \mathrm{~m}$

\begin{tabular}{|c|c|c|c|c|c|c|c|}
\hline No. & $\begin{array}{c}\text { Temp. } \\
{\left[{ }^{\circ} \mathrm{C}\right]}\end{array}$ & $\begin{array}{c}\text { BGA } \\
{\left[\mu \mathrm{g} / \mathbf{d m}^{3}\right]}\end{array}$ & $\begin{array}{c}\text { Chlorophyll } \\
{\left[\mu \mathrm{g} / \mathrm{dm}^{3}\right]}\end{array}$ & $\begin{array}{c}\mathrm{NH}_{4}^{+} \\
{\left[\mathrm{mg} / \mathrm{dm}^{3}\right]}\end{array}$ & $\begin{array}{c}\text { Conduct. } \\
{[\mu \mathrm{s} / \mathrm{cm}]}\end{array}$ & $\begin{array}{c}\text { pH } \\
{[-]}\end{array}$ & $\begin{array}{c}\text { Oxygen } \\
{\left[\mathrm{mg} / \mathrm{dm}^{3}\right]}\end{array}$ \\
\hline 1 & 22.2 & 1.53 & 1.28 & 0.20 & 273.7 & 9.35 & 11.83 \\
\hline 2 & 22.2 & 0.92 & 1.38 & 0.19 & 273.7 & 9.37 & 11.85 \\
\hline 3 & 22.2 & 1.10 & 1.31 & 0.19 & 273.7 & 9.37 & 11.85 \\
\hline 4 & 22.2 & 0.99 & 1.36 & 0.19 & 273.7 & 9.37 & 11.85 \\
\hline 5 & 22.2 & 0.76 & 0.94 & 0.23 & 273.4 & 9.31 & 11.86 \\
\hline 6 & 22.2 & 1.03 & 1.90 & 0.23 & 273.5 & 9.30 & 11.85 \\
\hline 7 & 22.2 & 1.01 & 1.57 & 0.23 & 273.5 & 9.30 & 11.85 \\
\hline 8 & 22.2 & 1.16 & 1.58 & 0.21 & 273.5 & 9.30 & 11.85 \\
\hline 9 & 22.2 & 0.74 & 1.58 & 0.18 & 273.5 & 9.37 & 11.84 \\
\hline 10 & 22.2 & 0.73 & 1.61 & 0.19 & 273.5 & 9.37 & 11.86 \\
\hline 11 & 22.2 & 1.00 & 1.62 & 0.19 & 273.5 & 9.37 & 11.85 \\
\hline 12 & 22.2 & 0.82 & 1.38 & 0.23 & 273.6 & 9.30 & 11.86 \\
\hline 13 & 22.2 & 0.83 & 1.62 & 0.22 & 273.4 & 9.32 & 11.87 \\
\hline 14 & 22.2 & 0.58 & 1.63 & 0.21 & 273.4 & 9.34 & 11.87 \\
\hline 15 & 22.2 & 0.56 & 1.57 & 0.19 & 273.4 & 9.38 & 11.87 \\
\hline 16 & 22.2 & 0.79 & 1.58 & 0.19 & 273.4 & 9.39 & 11.87 \\
\hline 17 & 22.2 & 1.51 & 1.52 & 0.19 & 273.4 & 9.39 & 11.87 \\
\hline
\end{tabular}

Table 2

Results of the measurements of water quality parameters with a probe towed with the speed $v=5.4 \mathrm{~km} / \mathrm{h}$

\begin{tabular}{|c|c|c|c|c|c|c|c|}
\hline No. & $\begin{array}{c}\text { Temp. } \\
{\left[{ }^{\circ} \mathrm{C}\right]}\end{array}$ & $\begin{array}{c}\text { BGA } \\
{\left[\mu \mathrm{g} / \mathbf{d m}^{3}\right]}\end{array}$ & $\begin{array}{c}\text { Chlorophyll } \\
{\left[\mu \mathrm{g} / \mathrm{dm}^{3}\right]}\end{array}$ & $\begin{array}{c}\mathrm{NH}_{4}^{+} \\
{\left[\mathrm{mg} / \mathbf{d m}^{3}\right]}\end{array}$ & $\begin{array}{l}\text { Conduct. } \\
{[\mu \mathrm{S} / \mathrm{cm}]}\end{array}$ & $\begin{array}{c}\text { pH } \\
{[-]}\end{array}$ & $\begin{array}{c}\text { Oxygen } \\
{\left[\mathrm{mg} / \mathrm{dm}^{3}\right]}\end{array}$ \\
\hline 1 & 22.3 & 1.14 & 1.30 & 0.22 & 273.8 & 9.29 & 11.48 \\
\hline 2 & 22.3 & 1.14 & 1.30 & 0.22 & 273.8 & 9.29 & 11.48 \\
\hline 3 & 22.3 & 1.03 & 1.37 & 0.23 & 275.4 & 9.29 & 11.47 \\
\hline 4 & 22.3 & 2.04 & 1.28 & 0.19 & 275.4 & 9.35 & 11.50 \\
\hline 5 & 22.3 & 1.07 & 1.36 & 0.19 & 275.4 & 9.36 & 11.52 \\
\hline 6 & 22.3 & 1.11 & 1.36 & 0.19 & 275.4 & 9.35 & 11.54 \\
\hline 7 & 22.3 & 1.39 & 1.25 & 0.22 & 273.8 & 9.27 & 11.61 \\
\hline 8 & 22.3 & 1.86 & 1.32 & 0.23 & 273.1 & 9.27 & 11.61 \\
\hline 9 & 22.3 & 1.84 & 1.32 & 0.23 & 273.1 & 9.28 & 11.61 \\
\hline 10 & 22.3 & 1.75 & 1.42 & 0.23 & 273.1 & 9.27 & 11.61 \\
\hline 11 & 22.3 & 1.76 & 1.43 & 0.20 & 273.1 & 9.35 & 11.61 \\
\hline 12 & 22.3 & 1.82 & 1.40 & 0.20 & 273.1 & 9.34 & 11.62 \\
\hline 13 & 22.3 & 1.86 & 1.43 & 0.20 & 273.1 & 9.34 & 11.64 \\
\hline 14 & 22.3 & 1.45 & 1.37 & 0.23 & 273.0 & 9.26 & 11.67 \\
\hline 15 & 22.3 & 1.49 & 1.42 & 0.22 & 272.7 & 9.29 & 11.66 \\
\hline 16 & 22.3 & 1.45 & 1.36 & 0.21 & 272.7 & 9.31 & 11.67 \\
\hline 17 & 22.3 & 1.30 & 1.41 & 0.19 & 272.7 & 9.36 & 11.68 \\
\hline 18 & 22.3 & 1.35 & 1.41 & 0.19 & 272.7 & 9.36 & 11.68 \\
\hline 19 & 22.2 & 1.44 & 1.40 & 0.19 & 272.7 & 9.36 & 11.68 \\
\hline 20 & 22.2 & 1.41 & 1.45 & 0.19 & 272.7 & 9.35 & 11.67 \\
\hline 21 & 22.2 & 1.05 & 1.33 & 0.23 & 275.1 & 9.27 & 11.71 \\
\hline 22 & 22.2 & 1.06 & 1.37 & 0.22 & 275.0 & 9.30 & 11.71 \\
\hline
\end{tabular}


Results of the measurements of water quality parameters with a probe towed with the speed $v=9 \mathrm{~km} / \mathrm{h}$

\begin{tabular}{|c|c|c|c|c|c|c|c|}
\hline No. & $\begin{array}{l}\text { Temp. } \\
{\left[{ }^{\circ} \mathrm{C}\right]}\end{array}$ & $\begin{array}{c}\text { BGA } \\
{\left[\mu \mathrm{g} / \mathbf{d m}^{3}\right]}\end{array}$ & $\begin{array}{c}\text { Chlorophyll } \\
{\left[\mu \mathrm{g} / \mathrm{dm}^{3}\right]}\end{array}$ & $\begin{array}{c}\mathrm{NH}_{4}^{+} \\
{\left[\mathrm{mg}^{+} \mathrm{dm}^{3}\right]}\end{array}$ & $\begin{array}{c}\text { Conduct. } \\
{[\mu S / \mathrm{cm}]}\end{array}$ & $\begin{array}{c}\text { pH } \\
{[-]}\end{array}$ & $\begin{array}{c}\text { Oxygen } \\
{\left[\mathrm{mg} / \mathrm{dm}^{3}\right]}\end{array}$ \\
\hline 1 & 22.3 & 2.84 & 1.21 & 0.18 & 273.2 & 9.37 & 22.3 \\
\hline 2 & 22.3 & 2.87 & 1.21 & 0.18 & 273.2 & 9.37 & 22.3 \\
\hline 3 & 22.3 & 2.94 & 1.24 & 0.19 & 273.2 & 9.37 & 22.3 \\
\hline 4 & 22.3 & 1.67 & 1.33 & 0.23 & 273.1 & 9.28 & 22.3 \\
\hline 5 & 22.3 & 1.93 & 1.34 & 0.22 & 273.1 & 9.31 & 22.3 \\
\hline 6 & 22.3 & 1.87 & 1.27 & 0.20 & 273.1 & 9.36 & 22.3 \\
\hline 7 & 22.3 & 2.07 & 1.32 & 0.19 & 273.1 & 9.36 & 22.3 \\
\hline 8 & 22.3 & 1.95 & 1.42 & 0.19 & 273.1 & 9.36 & 22.3 \\
\hline 9 & 22.3 & 1.94 & 1.34 & 0.19 & 273.1 & 9.37 & 22.3 \\
\hline 10 & 22.2 & 1.53 & 1.23 & 0.22 & 273.9 & 9.29 & 22.2 \\
\hline 11 & 22.2 & 0.94 & 1.24 & 0.23 & 275.4 & 9.28 & 22.2 \\
\hline 12 & 22.2 & 0.95 & 1.23 & 0.23 & 275.4 & 9.28 & 22.2 \\
\hline 13 & 22.2 & 0.95 & 1.24 & 0.23 & 275.4 & 9.28 & 22.2 \\
\hline 14 & 22.2 & 1.03 & 1.22 & 0.20 & 275.4 & 9.35 & 22.2 \\
\hline 15 & 22.2 & 1.31 & 1.22 & 0.20 & 275.4 & 9.35 & 22.2 \\
\hline 16 & 22.2 & 1.15 & 1.29 & 0.20 & 275.4 & 9.35 & 22.2 \\
\hline 17 & 22.2 & 1.70 & 1.42 & 0.23 & 273.8 & 9.28 & 22.2 \\
\hline 18 & 22.2 & 1.90 & 1.51 & 0.22 & 274.0 & 9.30 & 22.2 \\
\hline 19 & 22.2 & 1.96 & 1.50 & 0.21 & 274.0 & 9.32 & 22.2 \\
\hline 20 & 22.2 & 2.17 & 1.49 & 0.19 & 274.0 & 9.37 & 22.2 \\
\hline
\end{tabular}

Table 4

The value of the test function $u$, used to verify the hypothesis that the results obtained with stationary measurements at the depth of $h=1.5 \mathrm{~m}$ are not significantly different from the values obtained during towing the probe with the average speed of $v=5.4 \mathrm{~km} / \mathrm{h}\left(u_{\mathrm{kr}}=2.04\right)$

\begin{tabular}{|c|c|c|c|c|c|c|}
\hline \multirow{2}{*}{ No. } & \multirow{2}{*}{ Measured parameter } & \multicolumn{2}{|c|}{$\boldsymbol{h}=\mathbf{1 . 5} \mathbf{~ m}$} & \multicolumn{2}{c|}{$\boldsymbol{v}=\mathbf{5 . 4} \mathbf{~ k m} / \mathbf{h}$} & Value of function $\boldsymbol{u}$ \\
\cline { 3 - 6 } & & $\overline{\boldsymbol{x}}_{\mathbf{1}}$ & $\boldsymbol{\sigma}$ & $\overline{\boldsymbol{x}}_{\mathbf{2}}$ & $\boldsymbol{\sigma}$ & {$[-]$} \\
\hline 1 & Temperature $\left[{ }^{\circ} \mathrm{C}\right]$ & 22.23 & 0.55 & 22.26 & 0.46 & 0.17 \\
\hline 2 & BGA $\left[\mu \mathrm{g} / \mathrm{dm}^{3}\right]$ & 0.94 & 0.20 & 1.45 & 1.35 & 1.72 \\
\hline 3 & Chlorophyll $\left[\mu \mathrm{g} / \mathrm{dm}^{3}\right]$ & 1.50 & 0.24 & 1.37 & 0.63 & 0.88 \\
\hline 4 & Ammonia ion $\left[\mathrm{mg} / \mathrm{dm}^{3}\right]$ & 0.201 & 0.004 & 0.212 & 0.026 & 1.15 \\
\hline 5 & Conductivity $\left[\mu \mathrm{S} / \mathrm{cm}^{3}\right]$ & 273.5 & 8.0 & 273.7 & 5.5 & 0.06 \\
\hline 6 & $\mathrm{pH}[-]$ & 9.35 & 0.11 & 9.31 & 0.08 & 1.03 \\
\hline 7 & Oxygen conc. $\left[\mathrm{mg} / \mathrm{dm}^{3}\right]$ & 11.86 & 0.72 & 11.6 & 1.2 & 0.796 \\
\hline
\end{tabular}

Another hypothesis, stating that towing the probe with higher speed, i.e. $9 \mathrm{~km} / \mathrm{h}$ does not significantly affect the results of measurements was also verified. For this purpose, the authors tested the statistical hypothesis on the level of significance of $\alpha=0.05$ checking if results of measurement obtained during motorboat drive with the speed of $9 \mathrm{~km} / \mathrm{h}$ are significantly different from the results of stationary measurements with a motionless probe immersed to the depth of $h=1.5 \mathrm{~m}$.

Table 5 shows the results of calculations and values of the test function $u$ determined for each of the measured water quality parameters.

The data in Table 5 show that in the case of the BGA concentration, the test function $u$ exceed the critical value. We should therefore conclude that the BGA concentrations measured at the speed of $v=9 \mathrm{~km} / \mathrm{h}$ are not the same as in the case of a motionless probe. 
In the case of the remaining water quality parameters, the calculated values of the test function $u$ are less than the critical value $u_{k r}=2.04$.

The values of the test function $u$, used to verify the hypothesis that the results obtained with stationary measurements at the depth of $h=1.5 \mathrm{~m}$ are not significantly different from the values obtained during towing the probe with the speed of $v=9 \mathrm{~km} / \mathrm{h}\left(u_{k r}=2.04\right)$

\begin{tabular}{|c|c|c|c|c|c|c|}
\hline \multirow{2}{*}{ No. } & \multirow{2}{*}{ Measured parameter } & \multicolumn{2}{|c|}{$\boldsymbol{h} \mathbf{1 . 5} \mathbf{~ m}$} & \multicolumn{2}{|c|}{$\boldsymbol{v}=\mathbf{9} \mathbf{~ k m} / \mathbf{h}$} & Value of function $\boldsymbol{u}$ \\
\cline { 3 - 7 } & & $\overline{\boldsymbol{x}}_{\mathbf{1}}$ & $\boldsymbol{\sigma}$ & $\overline{\boldsymbol{x}}_{\mathbf{2}}$ & $\boldsymbol{\sigma}$ & {$[-]$} \\
\hline 1 & Temperature $\left[{ }^{\circ} \mathrm{C}\right]$ & 22.23 & 0.55 & 22.24 & 0.094 & 0.065 \\
\hline 2 & BGA $\left[\mu \mathrm{g} / \mathrm{dm}^{3}\right]$ & 0.94 & 0.20 & 1.78 & 0.67 & 5.38 \\
\hline 3 & Chlorophyll $\left[\mu \mathrm{g} / \mathrm{dm}^{3}\right]$ & 1.50 & 0.24 & 1.31 & 0.85 & 0.92 \\
\hline 4 & Ammonia ion $\left[\mathrm{mg} / \mathrm{dm}^{3}\right]$ & 0.20 & 0.004 & 0.21 & 0.026 & 0.86 \\
\hline 5 & Conductivity $\left[\mu \mathrm{S} / \mathrm{cm}^{3}\right]$ & 273.5 & 8.0 & 274.0 & 4.3 & 0.22 \\
\hline 6 & $\mathrm{pH}[-]$ & 9.35 & 0.11 & 9.33 & 0.07 & 0.55 \\
\hline 7 & Oxygen conc. $\left[\mathrm{mg} / \mathrm{dm}^{3}\right]$ & 11.86 & 0.72 & 11.80 & 0.13 & 0.32 \\
\hline
\end{tabular}

However, obtained results show that towing the probe at speed $v=9 \mathrm{~km} / \mathrm{h}$ has a significant effect on the results of measurements of BGA and distorts them and the results obtained at this speed can be encumbered with errors.

The two water quality parameters measured by the EXO-2 probe (chlorophyll concentration and BGA concentration) are based on the measurement of the intensity of fluorescence of organic matter particles, illuminated with a beam of light with specific wavelength [13]. This measurement can be disturbed by sunlight penetrating the water layer and entering the sensors measuring the intensity of fluorescence which means that reducing the depth of immersion of the EXO-2 probe can result in significant measurement errors. In order to determine the appropriate conditions for taking chlorophyll and algae concentration measurements, a series of stationary tests were performed at the depths of 1.5, 2.5 and $3.5 \mathrm{~m}$. The results of these measurements are presented in Table 6.

Table 6

Results of chlorophyll and BGA concentration measurements $\left[\mu \mathrm{g} / \mathrm{dm}^{3}\right]$ with a motionless probe immersed at different depths

\begin{tabular}{|c|c|c|c|c|c|c|}
\hline & \multicolumn{3}{|c|}{ Chlorophyll $\left[\boldsymbol{\mu g} / \mathbf{d m}^{\mathbf{3}}\right]$} & \multicolumn{3}{c|}{ Blue Green Algae [ $\boldsymbol{\mu g} / \mathbf{d m} \mathbf{3}^{\mathbf{3}}$} \\
\hline No. & $\boldsymbol{h} \mathbf{1 . 5} \mathbf{~ m}$ & $\boldsymbol{h} \mathbf{2 . 5} \mathbf{~ m}$ & $\boldsymbol{h} \mathbf{3 . 5} \mathbf{~ m}$ & $\boldsymbol{h}=\mathbf{1 . 5} \mathbf{~ m}$ & $\boldsymbol{h}=\mathbf{2 . 5} \mathbf{~ m}$ & $\boldsymbol{h}=\mathbf{3 . 5} \mathbf{~ m}$ \\
\hline 1 & 3.60 & 5.27 & 3.51 & 0.12 & 0.25 & 0.05 \\
\hline 2 & 3.31 & 5.57 & 8.31 & 0.18 & 0.19 & 0.25 \\
\hline 3 & 9.15 & 4.74 & 4.75 & 0.34 & 0.21 & 0.19 \\
\hline 4 & 5.59 & 7.65 & 5.67 & 0.23 & 0.38 & 0.18 \\
\hline 5 & 8.14 & 5.76 & 6.63 & 0.30 & 0.24 & 0.27 \\
\hline 6 & 5.27 & 6.60 & 8.54 & 0.21 & 0.27 & 0.45 \\
\hline 7 & 5.16 & 6.00 & 6.77 & 0.21 & 0.29 & 0.24 \\
\hline 8 & 4.27 & 6.14 & 7.49 & 0.16 & 0.20 & 0.37 \\
\hline 9 & 3.60 & 3.60 & 3.60 & 0.10 & 0.10 & 0.10 \\
\hline 10 & 7.10 & 7.10 & 6.30 & 0.30 & 0.20 & 0.20 \\
\hline 11 & 4.40 & 9.20 & 5.60 & 0.20 & 0.40 & 0.20 \\
\hline 12 & 4.70 & 5.70 & 4.80 & 0.20 & 0.20 & 0.20 \\
\hline 13 & 5.10 & 8.10 & 5.80 & 0.30 & 0.30 & 0.20 \\
\hline 14 & 5.80 & 8.50 & 6.60 & 0.30 & 0.50 & 0.30 \\
\hline 15 & 5.30 & 5.20 & 6.60 & 0.30 & 0.20 & 0.30 \\
\hline 16 & 5.00 & 7.50 & 6.80 & 0.20 & 0.40 & 0.30 \\
\hline
\end{tabular}


The evaluation of the significance of the effect of probe immersion depths on the results of measurements of chlorophyll and BGA concentrations in the Sulejow Reservoir requires the acceptance (or rejection) of the hypothesis that the results of measurements at different depths belong to the same population, i.e. that the calculated mean values of parameters measured with the probe immersed at the depth $h=1.5 \mathrm{~m}, 2.5 \mathrm{~m}$ and $3.5 \mathrm{~m}$ do not differ in any significant manner.

In order to verify hypothesis $H_{0}$ about the equivalence of mean values, described with equation (1), the test function (2) and methodology described above was be applied. The calculations use data sets obtained during stationary measurements made with a motionless probe, immersed at the depth of $h=1.5 \mathrm{~m}, h=2.5 \mathrm{~m}$ and $h=3.5 \mathrm{~m}$ (Table 6).

The $H_{0}$ hypothesis was formulated as follows: "The expected (mean) value calculated from the results of stationary measurements at the depth $h=1.5 \mathrm{~m}$ is not significantly different from the mean value calculated from measurements made at the depth of $h=2.5$ m, i.e. $\overline{x_{1}}(h 1.5)=\overline{x_{2}}(h 2.5)$. The hypothesis alternative to $H_{0}$ is $H_{1}$ is defined as: $H_{1}: \overline{\mathrm{x}_{1}}(\mathrm{~h} 1.5) \neq \overline{\mathrm{x}_{2}}(\mathrm{~h} 2.5)$.

Data from Table 6 were used to verify the $H_{0}$ hypothesis. For each of the measured chlorophyll and BGA concentrations, the value of test function $u$ described with the equation (2) was calculated and compared with the critical value of $u_{k r}$ read from $t$-Student tables. For the assumed level of confidence $\alpha=0.05$ and $n_{1}+n_{2}-2$ degrees of freedom, the critical value of test (2) is $u_{k r}=2.04$. Table 7 shows the results of calculations and values of the test function $u$ determined for chlorophyll and BGA concentration measurements made at the depths of $h=1.5 \mathrm{~m}$ and $h=2.5 \mathrm{~m}$.

The values of the test function $\mathrm{u}$, used to verify the hypothesis that the results obtained with stationary measurements at the depth of $h=1.5 \mathrm{~m}$ are not significantly different from the values obtained at the depth of $h=2.5 \mathrm{~m}\left(u_{k r}=2.04\right)$

\begin{tabular}{|c|c|c|c|c|c|c|}
\hline \multirow{2}{*}{ No. } & \multirow{2}{*}{ Measured parameter } & \multicolumn{2}{|c|}{$\boldsymbol{h}=\mathbf{1 . 5} \mathbf{~ m}$} & \multicolumn{2}{c|}{$\boldsymbol{h}=\mathbf{2 . 5} \mathbf{~ m}$} & Value of function $\boldsymbol{u}$ \\
\cline { 3 - 6 } & & $\overline{\boldsymbol{x}}_{\mathbf{1}}$ & $\boldsymbol{\sigma}$ & $\overline{\boldsymbol{x}}_{\mathbf{2}}$ & $\boldsymbol{\sigma}$ & $\boldsymbol{u}$ \\
\hline 1 & Chlorophyll $\left[\mu \mathrm{g} / \mathrm{dm}^{3}\right]$ & 5.3 & 1.5 & 6.4 & 1.4 & 2.02 \\
\hline 2 & BGA $\left[\mu \mathrm{g} / \mathrm{dm}^{3}\right]$ & 0.23 & 0.07 & 0.27 & 0.10 & 1.40 \\
\hline
\end{tabular}

The data presented in Table 7 show that in the case of the measured chlorophyll and BGA concentrations, the calculated value of the test function $u$ is lower than the critical value $u_{k r}=2.04$ which means that we cannot reject the hypothesis that the mean values calculated from the results of stationary measurements at the depth $h=1.5 \mathrm{~m}$ are not significantly different from the mean values calculated from the set of measurements made at the depth of $h=2.5 \mathrm{~m}$. The resulting conclusion is that decreasing the depth of immersion of the EXO-2 probe from the value of $h=2.5 \mathrm{~m}$ to $h=1.5 \mathrm{~m}$ does not significantly affect the results of measurements.

The tests also verified whether the decrease of probe immersion depth from $h=3.5 \mathrm{~m}$ to $2.5 \mathrm{~m}$ can distort the results of measurements. Table 8 displays the results of calculations and values of the test function $u$ determined for chlorophyll and BGA concentration measurements made at the depths of $h=2.5 \mathrm{~m}$ and $h=3.5 \mathrm{~m}$.

The data presented in Table 8 show that the measured values of the test function $u$ used to verify the hypothesis regarding the equivalency of the mean chlorophyll and BGA concentrations at the depths of $h=2.5 \mathrm{~m}$ and $h=3.5 \mathrm{~m}$ are lower than the critical value. 
This means that there is no reason to reject the hypothesis that the mean values from stationary measurements at the depth $h=2.5 \mathrm{~m}$ are not significantly different from the mean values from the measurements made at the depth of $h=3.5 \mathrm{~m}$. We can conclude that decreasing the depth of immersion of the EXO-2 probe from the value of $h=3.5 \mathrm{~m}$ to $h=2.5 \mathrm{~m}$ does not significantly affect the results of measurements.

Table 8

The values of the test function $u$, used to verify the hypothesis that the results obtained with stationary measurements at the depth of $h=2.5 \mathrm{~m}$ are not significantly different from the values obtained at the depth of $h=3.5 \mathrm{~m}\left(u_{k r}=2.04\right)$

\begin{tabular}{|c|c|c|c|c|c|c|}
\hline \multirow{2}{*}{ No. } & \multirow{2}{*}{ Measured parameter } & \multicolumn{2}{|c|}{$\boldsymbol{h}=\mathbf{2 . 5} \mathbf{~ m}$} & \multicolumn{2}{|c|}{$\boldsymbol{h = 3 . 5} \mathbf{~ m}$} & Value of function $\boldsymbol{u}$ \\
\cline { 3 - 7 } & & $\overline{\boldsymbol{x}}_{\mathbf{1}}$ & $\boldsymbol{\sigma}$ & $\overline{\boldsymbol{x}}_{\mathbf{2}}$ & $\boldsymbol{\sigma}$ & $\boldsymbol{u}$ \\
\hline 1 & Chlorophyll $\left[\mu \mathrm{g} / \mathrm{dm}^{3}\right]$ & 6.4 & 1.4 & 6.1 & 1.4 & 0.60 \\
\hline 2 & BGA $\left[\mu \mathrm{g} / \mathrm{dm}^{3}\right]$ & 0.27 & 0.10 & 0.24 & 0.09 & 0.97 \\
\hline
\end{tabular}

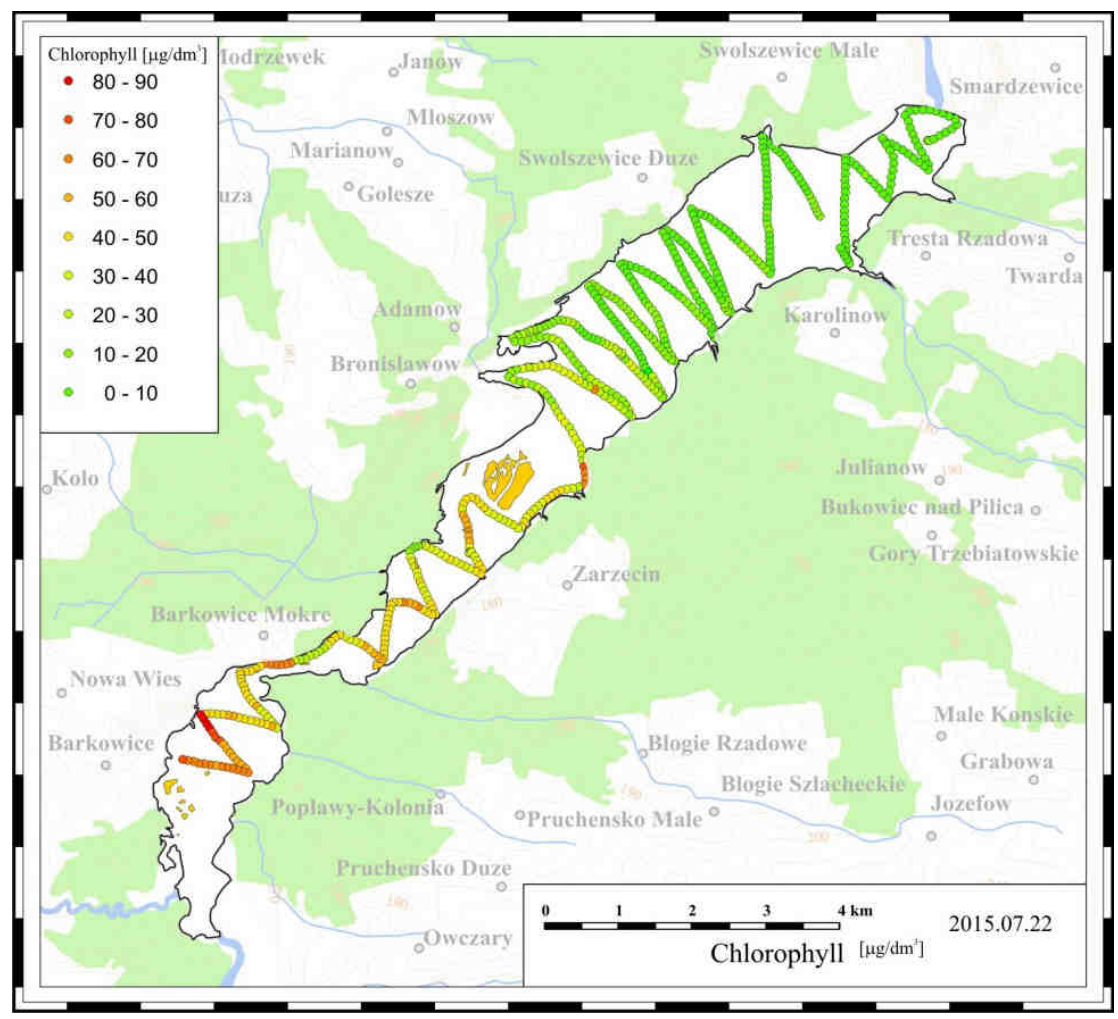

Fig. 3. Distribution of chlorophyll "a" in the Sulejow Reservoir (2015.07.22)

The probe with the data recording system enabled the measurement and recording the values together with the time and location (GPS) of measurement with the frequency of two minutes. Therefore, during one cruise, information regarding the quality of water on the day of measurement were collected in 650-700 points located across the entire Reservoir. In the 
summer season of 2015,12 cruises were completed, providing results from several thousand measurement points for further analysis.

The measured values were then processed at the Faculty of Geographical Sciences of the University of Lodz, using modern GIS database processing systems (ESRI ArcGIS) to transform each of the results into a spatial datum located on the surface of the Reservoir. The local data were interpolated using the ArcMap and Spatial Analyst software and visualized as maps [14]. The results are point maps presenting the values of each of the measured parameters along the route of the motorboat with the probe. Example of the results showing distribution of chlorophyll " $a$ " in the Sulejow Reservoir is shown in Figure 3.

\section{Conclusions}

The main objective of a monitoring measurements was to develop an auxiliary tool for the monitoring and prediction of surface water quality that can be applied to improve management of the large water bodies like e.g. Sulejow Reservoir.

Water management and controlling the conditions in the ecosystem of the large reservoirs requires acquisition of vast number of data which cannot be collected only from stationary measurements.

In the paper, the most appropriate conditions for mobile measurements - i.e. estimation of the optimal motorboat speed and depth of probe immersion to obtain similar accuracy as within stationary measurements were found. Statistical analysis confirmed that the results of mobile measurements at the depth $h=1.5 \mathrm{~m}$ with towing speed of the probe $5.4 \mathrm{~km} / \mathrm{h}$ do not differ from stationary measurements.

We also found that decreasing the depth of immersion of the EXO-2 probe from the value of $h=3.5 \mathrm{~m}$ to $h=2.5 \mathrm{~m}$ and to $h=1.5 \mathrm{~m}$ does not affect the results of the measurements of water quality parameters.

Final conclusion is, that speed of the motorboat during measurements of water quality parameters cannot be higher than around $5 \mathrm{~km} / \mathrm{h}$ to obtain similar results for stationary and mobile measurements. Application of this speed allows to collect 650-700 measuring points (7 water quality parameters together with the time and GPS location) across the entire reservoir during one day cruise.

Data collected during mobile measurements, after application of GIS processing systems (ESRI ArcGIS) transformed into a spatial datum located on the surface of the reservoir allow to make a map of water quality parameters in the water body.

The methodology of mobile monitoring measurements of water quality parameters with multiparameter probe which is compliant with the standards used in surface water monitoring studies is reported first time in the literature.

\section{Acknowledgments}

Research works presented in the paper was financed in frame of MONSUL project in the area PL 03 "Improvement of Environmental Control and Monitoring" in the programme of the Norwegian foundation EEA (EEA Funds 2009-2014).

The contractors in the MONSUL project express their gratitude to the Water Authority in Smardzewice for all the assistance during works on the reservoir. 


\section{References}

[1] Kagami M, Hirose Y, Ogura H. Phosphorus and nitrogen limitation of phytoplankton growth in eutrophic Lake Inba, Japan. Limnology. 2013;14:51-58. DOI: 10.1007/s10201-012-0385-5.

[2] Jachniak E, Kozak JL. Estimating the level of water eutrophication in Poraj dam reservoir based on selected methods. Ecol Chem Eng A. 2013;20;7-8:779-790. DOI: 10.2428/ecea.2013.20(07)071.

[3] Zieminska-Stolarska A, Zbicinski I, Imbierowicz M, Skrzypski J. Waterpraxis as a tool supporting protection of water in the Sulejow Reservoir. Desalin Water Treat. 2013;51(19-21):4194-4206. DOI: 10.1080/19443994.2013.768043.

[4] Mankiewicz-Boczek J, Jaskulska A, Pawełczyk J, Gągała I, Serwecińska L, Dziadek J. Cyanophages infection of microcystis bloom in lowland dam reservoir of Sulejow, Poland. Microb Ecol. 2016;71(2):315-25. DOI: 10.1007/s00248-015-0677-5.

[5] Bukowska A, Kaliński T, Koper M, Kostrzewska-Szlakowska I, Kwiatowski J, Mazur-Marzec H, et al. Predicting blooms of toxic cyanobacteria in eutrophic lakes with diverse cyanobacterial communities. Scientific Reports 7, Article number: 8342 (2017). DOI: 10.1038/s41598-017-08701-8.

[6] Grabowska M. The role of a eutrophic lowland reservoir in shaping the composition of river phytoplankton. Ecohydrol Hydrobiol. 2012;12(3):231-242. DOI: 10.2478/v10104-012-0016-0.

[7] Szulc B, Jurczak T, Szulc K, Kaczkowski Z. The influence of the ecohydrological rehabilitation in the cascade of Arturowek reservoirs in Lodz (Central Poland) on the cyanobacterial and algae blooming. Oceanolog Hydrobiol Stud. 2015;44(2):236:244. DOI: 10.1515/ohs-2015-0022.

[8] Glasgow HB, Burkholder JM, Reed RE, Lewitus AJ, Kleinmann JE. Real-time remote monitoring of water quality: a review of current applications, and advancements in sensor, telemetry, and computing technologies. J Experim Marine Biol Ecol. 2004;300(1/2):409-448. DOI: 10.1016/j.jembe.2004.02.022

[9] Tuna G, Arkoc O, Gulez K. Continuous monitoring of water quality using portable and low-cost approaches. Int J Distributed Sensor Networks. 2013;9(6):1-11. DOI: 10.1155/2013/249598.

[10] YSI Application notes, 1 - Catchment Monitoring Network Protects Thames River, C2008 YSI Environmental web. www.environment-agency.gov.uk - A566.

[11] YSI Application notes 2 - Water Quality Is Key to the Success of Cardiff Bay Restoration, C2011 YSI Environmental web, www.ysihydrodata.com - A592, Cardiff Harbour Authority's website: www.cardiffharbour.com.

[12] Absalon D, Ruman M, Matysik M, Koziol K, Polkowska Z. Innovative solutions in surface water quality monitoring. APCBEE Procedia. 2014;10:26-30. DOI: 10.1016/j.apcbee.2014.10.009.

[13] Torbick N, Feng H, Zhang J, Qi J, Zhang H, Becker B. Mapping chlorophyll-a concentrations in West Lake, China using Landsat 7 ETM+. J Great Lakes Res. 2008;34(3):559-565. DOI: 10.3394/0380-1330(2008)34[559:MCCIWL]2.0.CO;2.

[14] Ho J, Michalak A. Challenges in tracking harmful algal blooms: A synthesis of evidence from Lake Erie. J Great Lakes Res. 2015;41(2):317-325. DOI: 10.1016/j.jglr.2015.01.001. 